\title{
Pyro and Kinetic Studies of Barium Oxalate Crystals Grown in Agar Gel
}

\author{
Paresh V. Dalal ${ }^{*}$, Kishor B. Saraf ${ }^{1}$, Navinchandra G. Shimpi ${ }^{2}$, Navneet R. Shah ${ }^{1}$ \\ ${ }^{1}$ P. G. Department of Physics, Pratap College, Amalner, India; ${ }^{2}$ University Department of Chemical Technology, North Maharashtra \\ Univeristy, Jalgaon, India. \\ Email: *paresh10dalal@gmail.com
}

Received May $2^{\text {nd }}, 2012$; revised June $5^{\text {th }}, 2012$; accepted July $1^{\text {st }}, 2012$

\begin{abstract}
Single crystals of barium oxalate have been grown using gel method at ambient temperature. Thermal characteristics and kinetic parameters of barium oxalate crystals were determined by thermo-gravimetric (TG) analysis under non-isothermal heating conditions. The pyrolysis experiments were performed with increasing temperature up-to $600^{\circ} \mathrm{C}$ at heating rate of $5^{\circ} \mathrm{C}, 7^{\circ} \mathrm{C}$ and $10^{\circ} \mathrm{C}$ in nitrogen gas atmosphere. The pyrolysis curve showed that loss of mass took place mainly in the range of $220^{\circ} \mathrm{C}-400^{\circ} \mathrm{C}$. At higher temperature there was a significant mass loss due to decomposition of oxalates. Ozawa and Coats \& Redfern methods were used to determine the apparent activation energies of material degradation. The apparent activation energies for barium oxalate crystals were obtained $187.42 \mathrm{KJ} \cdot \mathrm{mol}^{-1}$ and 185.4 $\mathrm{KJ} \cdot \mathrm{mol}^{-1}$ for the respective methods.
\end{abstract}

Keywords: Barium Oxalate; Thermo-Gravimetric Analysis; Kinetic Studies; Thermodynamic Parameters

\section{Introduction}

In the continued demand of materials having more stability even up to high temperature, high resistance to heat and hard, for their applications in pyrotechnic and ceramic industries, the research and development of barium oxalate was a significant step [1]. With its excellent thermal stability and hardness, this material has found a wide range of applications in fire creeker industries as a pyro colorant [2], and to improve hardness of barium titinate in capacitor industries [3]. Nano-particles of barium oxalate [4] and barium titanyl oxalate have shown its effect on semiconducting properties [5].

Well facet prismatic, platy shaped transparent crystals were grown by gel method using agar-agar gel as a media of growth at ambient temperature [6].

Since barium oxalate is a pyro-nature material, which shows great promise in pyrotechnic and high temperature electronic applications. It is therefore interesting to investigate the thermal stability and degradation reaction mechanism of this material.

Pyro and kinetic studies such as decomposition rate and activation energy are important parameters to determine the reaction mechanism in solid phases. The use of thermo-gravimetric data to evaluate the kinetic parameters of solid state reactions involving weight loss has

${ }^{*}$ Corresponding author. been investigated by many workers [7-11]. If the pyrolysis occurs through a many stepped mechanism, usually, the shape of the curve can be determined by the kinetic parameters of pyrolysis, such as order of reaction, frequency factor and energy of activation. Successful and deliberate attempts to evaluate kinetic and thermodynamic parameters were made by Kotru et al. [12], Arora et al. [13], and Schaube et al. [14]. The kinetics of dehydration of gypsum [15], lithium sulphate monohydrate crystal [16], and the kinetic and thermodynamic parameters of decomposition of chromium chromate in different gas atmospheres have been evaluated [17].

Usually, kinetic parameters can be calculated from the TG curves by applying integral and differential equations [7-9], which are proposed by different authors on the basis of different assumptions to the kinetics of the reaction and the Arrhenius law. However, in the present investigation, the Ozawa [18] and the Coats \& Redfern method [7], is an integral approach has been used to elucidate the thermal stability, the nature and extent of the degradation of barium oxalate in nitrogen atmosphere. In addition, thermodynamic parameters were also evaluated.

\section{Experimental}

The thermo-gravimetric curves were obtained by employing a "TA-2050" thermal analyzer under various heating rates in nitrogen gas atmosphere. About $10-14$ 
mg material was used for each measurement. The integral residual weights were recorded in between $30^{\circ} \mathrm{C}$ to $600^{\circ} \mathrm{C}$. However, the kinetic data analysis was performed based on the results obtained between $220^{\circ} \mathrm{C}$ to $400^{\circ} \mathrm{C}$, where the rigorous reaction actually took place. Three heating rates $5^{\circ} \mathrm{C} / \mathrm{min}, 7^{\circ} \mathrm{C} / \mathrm{min}$ and $10^{\circ} \mathrm{C} / \mathrm{min}$ were employed as shown in Figure 1. From these TG curves kinetic and thermodynamic parameters were evaluated by applying Ozawa and Coats \& Redfern method.

\subsection{The Ozawa Method}

The Ozawa method has been widely used for kinetic data analysis $[19,20]$. This integral method compared heating rates with temperatures under the same conversion rates. The kinetic parameters of dehydration process of barium oxalate crystals were evaluated by using Ozawa equation

$$
\log \beta=\log \left(\frac{A E}{R}\right)-2.315-0.4567\left(\frac{E}{R T}\right)-\log (a)
$$

where $\beta$ is the heating rate $\left(\mathrm{K} \cdot \mathrm{min}^{-1}\right), A$ is the pre-exponential factor $\left(\mathrm{min}^{-1}\right), R$ is the gas constant $(8.314$ $\left.\mathrm{Jmol}^{-1} \cdot \mathrm{K}^{-1}\right), E$ is the energy of activation, and

$$
\begin{gathered}
g(a)=(A E / \beta R) P(x) \\
X=E / R T
\end{gathered}
$$

and $\alpha$ is the fraction of decomposed material, which is given by

$$
\alpha=\left(W_{0}-W_{t}\right) /\left(W_{0}-W_{f}\right)
$$

where $W_{0}$ is the initial mass of the sample, $W_{t}$ is the mass of the sample at temperature $t$ and $W_{f}$ is the final mass at a temperature at which the mass loss is approximately unchanged.

By plotting graphs between $\log \beta$ versus $1 / T$ into a different straight line at different conversion rates as shown in Figure 2, the activation energy $E$ and frequency factor $\log A$ could thus be obtained from the slope and the intercept respectively.

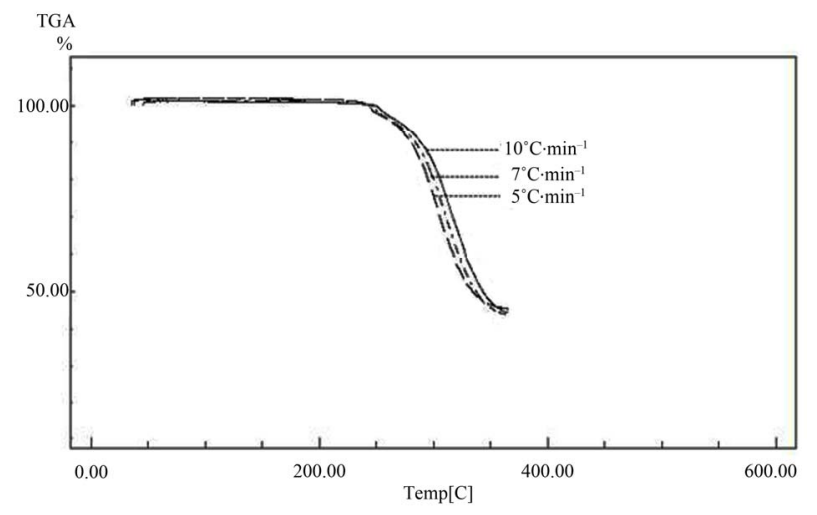

Figure 1. The thermogravimetric curves at three different rates.

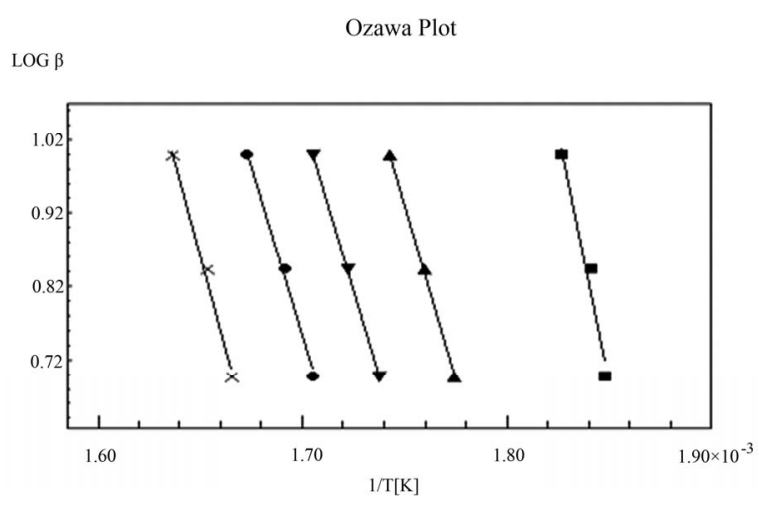

Figure 2. Variation of $\log \beta$ (heating rate) as a function of $1000 / T$.

\subsection{The Coats $\&$ Redfern Method}

Coats \& Redfern method is also an integral method, and it involves the thermal degradation mechanism [21,22]. The kinetic parameters of dehydration process can be evaluated by using the relation as

$$
\begin{aligned}
& \log _{10}\left[\left(\frac{\left\{1-(1-\propto)^{1-n}\right\}}{T^{2}(1-n)}\right)\right] \\
& =\left[\log _{10}\left\{\left(\frac{A R}{\beta E}\right)\left(1-\frac{2 R T}{E}\right)\right\}-\left(\frac{E}{2.303 R T}\right)\right]
\end{aligned}
$$

for $n \neq 1$

To determine the value of activation energy and order of reaction " $n$ ", a plot of $\left[\frac{\left\{1-(1-\propto)^{1-n}\right\}}{T^{2}(1-n)}\right]$ versus $1 / T$ is drawn for different values of $n$ (Figure 3). The best linear fit gives the correct value of $n$. The value of activation energy can be calculated from the slope of a linear plot. The value of frequency factor can be obtained from Equation (5). Equation (5) is applied for all values of $n$, except $n=1$. For $n=1$, the modified equation has been proposed [7].

$$
\begin{aligned}
& \log _{10}\left[\frac{-\log (1-\propto)}{T^{2}}\right] \\
& =\left[\log _{10}\left\{\left(\frac{A R}{\beta E}\right)\left(1-\frac{2 R T}{E}\right)\right\}-\left(\frac{E}{2.303 R T}\right)\right] \\
& \text { for } n=1
\end{aligned}
$$

The other kinetic analysis parameters such as enthalpy of activation $\left(\Delta H^{*}\right)$, entropy of activation $\left(\Delta S^{*}\right)$ and free energy change of decomposition $\left(\Delta G^{*}\right)$ were evaluated [23] using equations

$$
\Delta H^{*}\left(\mathrm{KJ} \cdot \mathrm{mol}^{-1}\right)=E+\Delta n R T
$$




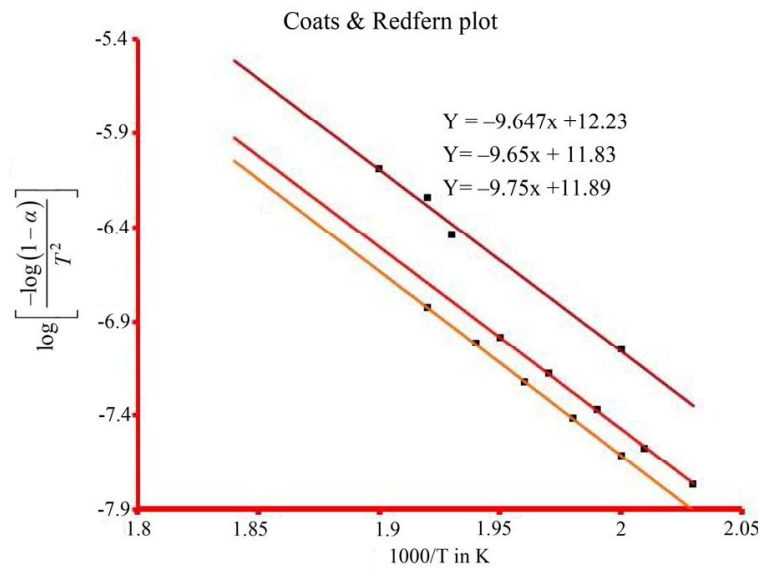

Figure 3. $\log \left[\frac{-\log (1-\alpha)}{T^{2}}\right]$ as a function of $1000 / T$.

where $\Delta n=$ Number of moles of product - number of moles of reactant in the reaction

$$
\begin{gathered}
\Delta S^{*}\left(\mathrm{JK}^{-1} \cdot \mathrm{mol}^{-1}\right)=2.303 R[\log (A h / K T)] \\
\Delta G^{*}\left(\mathrm{KJ} \cdot \mathrm{mol}^{-1}\right)=\Delta H^{*}-T \Delta S^{*}
\end{gathered}
$$

where $A$ is (Arrhenius constant) determined from the intercept, $K$ is Boltzmann and $h$ is Plank's constant.

\section{Results and Discussion}

Figure 1 shows the non-isothermal degradation behavior of barium oxalate crystals at the various heating rates. It has been clearly evidenced that the sample displayed excellent thermal stability. When the heating rate was chosen $10^{\circ} \mathrm{C} / \mathrm{min}$, the residual weight along testing temperature can be used to depict the thermal properties. The initial decomposition temperature or the onset weight loss of sample was about $220^{\circ} \mathrm{C}$. The temperature that corresponds to the maximum weight loss rate was around $320^{\circ} \mathrm{C}$. The decomposition process slowed down after reaching $370^{\circ} \mathrm{C}$. The residual weight was $48 \%$ when heated upto $400^{\circ} \mathrm{C}$. The reaction appeared to be a one stage reaction in nitrogen atmosphere.

The analysis of reaction kinetic parameters was performed on the thermo-gravimetric curves, obtained between $220^{\circ} \mathrm{C}$ to $400^{\circ} \mathrm{C}$, using Ozawa and Coats \& Redfern methods.

In Ozawa method, the plot of log (heating rate) versus $1000 / T$ is provided in Figure 2. Five different conversion rates ranging from 0.1 to 0.6 were used for data analysis. Three different heating rates were used in this analysis, including $5^{\circ} \mathrm{C}, 7^{\circ} \mathrm{C}$, and $10^{\circ} \mathrm{C} / \mathrm{min}$. The slopes of these five straight lines have been used to calculate activation energy $(E)$ and their intercepts were used to calculate frequency factor $(\log A)$. The other kinetic parameters such as enthalpy of activation $\left(\Delta H^{*}\right)$, entropy of activation $\left(\Delta S^{*}\right)$, and free energy change of decomposition $\left(\Delta G^{*}\right)$ were calculated using Equations (7)-(9) and are represented in Table 1. Figure 3 is the best linear fitted plot obtained using Equation (6) for Coats \& Redfern method. The slopes of these straight lines have been used to calculate activation energy $(E)$ and their intercepts were used to calculate frequency factor $(\log A)$. The average calculated activation energy, frequency factor and other thermodynamic parameters were also depicted in Table 1.

According to Table 1, the activation energy values calculated from Ozawa and Coats \& Redfern methods were found to be $187.4 \mathrm{KJ} \cdot \mathrm{mol}^{-1}$ and $185.4 \mathrm{KJ} \cdot \mathrm{mol}^{-1}$ respectively, which seem to be in good agreement with each other. The positive value of $\Delta \mathrm{H}^{*}$ indicate that the dissociation processes are endothermic in nature and enhanced with the rise of temperature. $\Delta G^{*}$ values are positive, thus dissociation processes are non-spontaneous [24]. The positive values of $\Delta S^{*}$ indicate that the activated complex has a less ordered structure than the reactants [25] and further the high values of $A$ indicate the fast nature of the reaction [25].

\section{Conclusions}

In summary, the kinetic and thermodynamic parameters evaluated from the thermodynamic curves by applying Ozawa and Coats \& Redfern relations were performed between $220^{\circ} \mathrm{C}$ to $400^{\circ} \mathrm{C}$. Following are the point wise conclusions:

1) The major thermal degradation reaction appeared to be a one stage reaction.

2) In the decomposition reaction, the main reason of mass loss corresponding to decomposition of oxalates into barium carbonate by releasing carbon monoxide. This carbonate is used as a pyro-colorant to produce green colour in fire creekers as well as in signaling [2].

3) High activation energy, thus explained high degree of thermal stability and resistance to heat, which lead its application to improve hardness of barium titanate in

Table 1. Kinetics and thermodynamic parameters of dehydration of barium oxalate.

\begin{tabular}{ccccccc}
\hline Method & $\boldsymbol{K}\left(\mathbf{m i n}^{-\mathbf{1}}\right)$ & $\boldsymbol{E}(\mathbf{K J} / \mathbf{m o l e})$ & $\Delta \boldsymbol{H}(\mathbf{K J} / \mathbf{m o l e})$ & $\Delta \boldsymbol{S}\left(\mathbf{J} / \mathbf{m o l e} \cdot \mathbf{K}^{\mathbf{0}}\right)$ & $\Delta \boldsymbol{G}(\mathbf{K J} / \mathbf{m o l e})$ & Frequency factor $(\boldsymbol{A})$ \\
\hline Ozawa & $1.12 \times 10^{10}$ & 187.42 & 183.4 & 63.1 & 152.6 & $2.02 \times 10^{16}$ \\
Coats \& Redfern & $1.8 \times 10^{10}$ & 185.4 & 181.1 & 62.7 & 148.7 & $7.7 \times 10^{16}$ \\
\hline
\end{tabular}


capacitors [3].

4) The thermodynamic parameters suggest that the enthalpy increases during the process is of endothermic in nature, whereas fast and nonspontaneous type nature of reaction.

\section{Acknowledgements}

The corresponding author is thankful to Dr. S. Mishra, Head, University Department of Chemical Technology, North Maharashtra University, Jalgaon for providing laboratory facilities.

\section{REFERENCES}

[1] P. V. Dalal and K. B. Saraf, "Growth and Study of Barium Oxalate Single Crystals in Agar Gel," Bulletin of Material Science, Vol. 29, No. 5, 2006, pp. 421-425. doi:10.1007/BF02914071

[2] A. M. Helmenstine, "Chemistry of Firework Colors," The New York Times Company, New York, 2012.

http://chemistry.about.com/od/fireworks/pyrotechniques/a /fireworkcolours.htm

[3] J. Bera and D. Sarkar, "Formation of $\mathrm{BaTiO}_{3}$ from Barium Oxalate and $\mathrm{TiO}_{2}$," Journal of Electroceramics, Vol. 11, No. 3, 2003, pp. 131-137. doi:10.1023/B:JECR.0000026366.17280.0d

[4] P. Sharma and H. S. Virk, "Fabrication of Nanoparticles of Barium Carbonate/Oxalate Using Reverse Micelle Technique," The Open Surface Science Journal, Vol. 1, 2009, pp. 34-39. doi:10.2174/1876531900901010034

[5] R. A. Kimel, V. Ganine and J. H. Adair, "Double Injection Synthesis and Dispersion of Submicrometer Barium Titanyl Oxalate Tetrahydrate," Journal of the American Ceramic Society, Vol. 84, No. 5, 2001, pp. 1172-1174. doi:10.1111/j.1151-2916.2001.tb00809.x

[6] P. V. Dalal, K. B. Saraf and S. Shah, "Growth of Barium Oxalate Crystals in Agar-Agar Gel and Their Characterization," Crystal Research and Crystal Technology, Vol. 44, No. 1, 2009, pp. 36-42. doi:10.1002/crat.200800221

[7] A W. Coats and J. P. Redfern, "Kinetic Parameters from Thermogravimetric Data," Nature, Vol. 201, No. 4914, 1964, pp. 68-69. doi:10.1038/201068a0

[8] H. H. Horowitz and G. Metzger, "A New Analysis of Thermogravimetric Traces," Analytical Chemistry, Vol. 35, No. 10, 1963, pp. 1464-1468. doi:10.1021/ac60203a013

[9] E. S. Freeman and B. Carroll, "The Application of Thermoanalytical Decomposition of Calcium Oxalate Monohydrate," Journal of Physical Chemistry, Vol. 62, 1958, pp. 394-397. doi:10.1021/j150562a003

[10] D. W. van Krevelan, C. van Heerdeen and F. J. Huntjens, "Physiochemical Aspects of the Pyrolysis of Coal and Related Organic Compounds," Fuel, Vol. 30, 1951, pp. 253.

[11] D. Dollimore, D. L. Griffiths and D. Nicholson, "The thermal Decomposition of Oxalates. Part II. Thermogra- vimetric Analysis of Various Oxalates in Air and in Nitrogen," Journal of the Chemical Society, 1963, pp. 2617 2623. doi:10.1039/jr9630002617

[12] P. N. Kotru, K. K. Raina and M. L. Koul, "The Kinetics of Solid-State Decomposition of Neodymium Tartrate," Indian Journal of Pure and Applied Physics, Vol. 25, 1987, p. 220.

[13] S. K. Arora, Vipul Patel and A. Kothari, "Kinetics and Mechanism of Thermal Decomposition of Strontium Tartrate Crystals," Materials Chemistry and Physics, Vol. 84, 2004, pp. 323-330.

doi:10.1016/j.matchemphys.2003.10.017

[14] F. Schaube, L. Koch, A. Wörner and H. Müller-Steinhagen, "A Thermodynamic and Kinetic Study of the Deand Rehydration of $\mathrm{Ca}(\mathrm{OH})_{2}$ at High $\mathrm{H}_{2} \mathrm{O}$ Partial Pressures for Thermo-Chemical Heat Storage," Thermochimica Acta, Vol. 538, 2012, pp. 9-20. doi:10.1016/j.tca.2012.03.003

[15] D. Fatu, "Kinetics of Gypsum Dehydration," Journal of Thermal Analysis and Calorimetry, Vol. 65, No. 1, 2001, pp. 213-220. doi:10.1023/A:1011597106589

[16] N. Modestov, P. V. Poplankhin and N. Z. Lyakhov, "Dehydration Kinetics of Lithium Sulfate Monohydrate Single Crystals," Journal of Thermal Analysis and Calorimetry, Vol. 65, No. 1, 2001, pp. 121-130. doi:10.1023/A:1011576502046

[17] S. A. Halawy, N. E. Fouad, M. A. Mohamed and M. I. Zaki, "Kinetic and Thermodynamic Parameters of the Decomposition of Chromium Chromate in Different Gas Atmospheres," Journal of Thermal Analysis and Calorimetry, Vol. 65, No. 1, 2001, pp. 167-176. doi:10.1023/A:1011536920701

[18] T. Ozawa, "A New Method of Analyzing Thermogravimetric Data," Bulletin of the Chemical Society of Japan, Vol. 38, No. 11, 1965, pp. 1881-1886. doi: $10.1246 /$ bcsj.38.1881

[19] M. Gogebakan and O. Uzun, "Thermal Stability and Mechanical Properties of Al-Based Amorphous Alloys," Journal of Materials Processing Technology, Vol. 153, 2004, pp. 829-832. doi:10.1016/i.jmatprotec.2004.04.012

[20] J. D. Cooney and D. M. Wiles, "Thermal Degradation of Poly(ethylene terephthalate): A Kinetic Analysis of Thermoravimetric Data," Journal of Applied Polymer Science, Vol. 28, 1983, pp. 2887-2902.

doi:10.1002/app.1983.070280918

[21] K. J. Laidler, "Chemical Kinetics," 3rd Edition, Harper \& Row, New York, 1987.

[22] R. M. Dabhi and M. J. Joshi, "Thermal Studies of Gel Grown Zinc Tartrate Spherulites," Indian Journal of Physics, Vol. 76A, No. 2, 2002, pp. 211-213.

[23] F. Yakuphanoglu, A. O. Gorgulu and A. Cukurovali, "An Organic Semiconductor and Conduction Mechanism: N[5-methyl-1,3,4-tiyodiazole-2-yl] Ditiyocarbamate ComPound," Physica B: Condensed Matter, Vol. 353, No. 3-4, 2004, pp. 223-229. doi:10.1016/j.physb.2004.09.099

[24] S. Mallakpour and M. Dinari, "Eco-Friendly Fast Synthesis and Thermal Degradation of Optically Active Polyamides under Microwave Accelerating Conditions," Chi- 
nese Journal of Polymer Science, Vol. 28, No. 5, 2010, pp. 685-694. doi:10.1007/s10118-010-9120-z

[25] K. G. Mallikarjun, "Thermal Decomposition Kinetics of
Ni(II) Chelates of Substituted Chalcones," E-Journal of Chemistry, Vol. 1, No. 2, 2004, pp. 105-109.

doi: $10.1155 / 2004 / 385034$ 